\title{
Modelo sistêmico de ocorrência de ações coletivas: um estudo multicaso na comercialização de frutas, legumes e verduras
}

\author{
Cooperation in marketing channels: a multicase \\ study on fresh fruit and vegetable marketing
}

\author{
Andrea Lago da Silva ${ }^{1}$ \\ Ana Elisa Bressan Smith Lourenzani²
}

\begin{abstract}
Resumo: A cooperação desempenha um papel de grande relevância para a participação competitiva de indivíduos e empresas na atividade econômica, especialmente nas condições de um ambiente dinâmico e cercado de incertezas, como é o caso do setor de FLV. Assim, o principal objetivo dessa pesquisa foi elaborar um modelo sistêmico capaz de demonstrar as relações causais (interdependências) entre as variáveis de ocorrência da cooperação. Com base na confrontação teoria-pesquisa empírica, foram analisados os relacionamentos interorganizacionais horizontais e verticais a partir da análise de dez estudos de caso realizados em cinco regiões brasileiras. A partir dessa análise, foi possível elaborar um modelo sistêmico que demonstrava a existência de relações causais entre as variáveis de ocorrências da cooperação. Sob o ponto de vista sistêmico, na medida em que as variáveis estão inter-relacionadas, interferências externas ou decisões dos agentes resultam em ajustes em todo o sistema. Assim, há uma importante oportunidade para ações de políticas públicas e estratégias privadas visando à utilização de sistemas de comercialização inovadores.
\end{abstract}

Palavras-chave: Cooperação. Canais de distribuição. Frutas, legumes e verduras. Pequeno produtor.

\begin{abstract}
Cooperation plays an important role in the competitive participation of individuals and firms in the economic activity, especially in dynamic and uncertain environments such as the Fresh Fruit and Vegetable (FFV) market in Brazil. Therefore, the main objective of this research was to develop a systemic model able to demonstrate causal interdependencies between cooperation occurrence variables. The systemic model revealed several collective action occurrence variables as well their interdependencies, identified in the literature and in the empirical study. From a systemic point of view, depending on how they are interrelated, changes in the variables or in the agents behaviour can lead to adjustments in the system. Thus, since the variables are dynamic, external interferences or agents' decisions may affect the whole collective action. This is an important opportunity for public and private politics action focusing on innovative commercialization systems.
\end{abstract}

Keywords: Cooperation. Marketing channel. Fresh fruit and vegetable. Small grower.

\section{Introdução}

A horticultura pode ser caracterizada sob dois aspectos: é intensiva em mão de obra e apresenta reduzida escala mínima de produção para que a atividade seja rentável. Devido a essas características, representa uma importante alternativa para pequenos produtores e para a agricultura familiar. Além disso, é um grande empregador de mão de obra no campo, ajudando a evitar problemas de êxodo rural e a melhorar a distribuição de renda.

Pequenos empreendimentos rurais encontram dificuldades em atender aos requisitos impostos pelos canais de distribuição, principalmente pelas grandes redes varejistas de autosserviço; por outro lado, tais empreendimentos são considerados mais flexíveis para se adaptarem a situações de demanda instável (NORONHA VAZ, 2002). De acordo com essa autora, a maior flexibilidade é traduzida numa adaptabilidade, que cria novas formas gerenciais. Essas formas gerenciais envolvem novas técnicas de produção, novos produtos, novas formas de organização interna e novas parcerias. Essas formas poderiam operacionalizar a coordenação eficiente das cadeias ou das redes de suprimentos dos produtos hortícolas. Entretanto, para atender às exigências impostas pelo varejo é necessário que haja investimentos, além de obtenção de economias de escala e escopo, o que parece ser difícil

\footnotetext{
Departamento de Engenharia de Produção, Universidade Federal de São Carlos - UFSCar, Rod. Washington Luis, Km 235, CEP 13565-905, São Carlos, SP, Brasil, E-mail: deialago@ufscar.br

${ }^{2}$ Administração, Campus Experimental de Tupã, Universidade Estadual Paulista Júlio de Mesquita Filho - UNESP, Av. Domingos da Costa Lopes, 780, Jd. Unesp, CEP 17602-496, Tupã, SP, E-mail: anaelisa @tupa.unesp.br
}

Recebido em 25/5/2009 — Aceito em 29/9/2010

Suporte financeiro: CNPq. 
para o pequeno produtor que atua individualmente. Até mesmo alguns canais alternativos apontados por Machado (2004), como a venda direta para outros formatos de varejo (varejões e sacolões), o fornecimento para empresas de refeições coletivas e a venda direta de cestas de produtos para o consumidor final, exigem investimentos que podem dificultar o acesso a esses canais.

Para possibilitar a inserção desses produtores no processo de aquisição de produtos das grandes redes varejistas e de outros importantes canais de distribuição, sugere-se a adoção de ações coletivas, na forma de arranjos cooperativos. As ações realizadas horizontalmente dentro de determinado elo afetam verticalmente o desempenho da cadeia (LAZZARINI; CHADDAD; COOK, 2001) e no caso das redes no setor agrícola e de alimentos, são criadas, principalmente, com propósitos estratégicos, buscando desenvolver estratégias de diferenciação e ressaltar competências essenciais (SAUVÉE, 2001).

Farina (2002) identificou que ações coletivas podem representar uma estratégia para atender às exigências impostas pelo varejo. Segundo essa autora, tais ações são importantes não somente para a aquisição de insumos ou para atingir escala de comercialização, mas para adaptar os pequenos produtores aos novos padrões competitivos. Assim, a cooperação entre agentes do mesmo elo nas cadeias produtivas e entre agentes de diferentes elos consiste em alternativas viáveis para pequenos produtores, visando não só a sua inserção nos principais canais de distribuição, mas também a melhoria do seu bem-estar social.

Dessa forma, torna-se relevante analisar as exigências impostas pelos diferentes canais de distribuição e a capacidade de resposta de pequenos empreendimentos agrícolas que atuam de forma colaborativa com outros agentes do mesmo elo (horizontalmente) e/ ou em parceria com elos a montante ou a jusante (verticalmente). Com base na cooperação, esses empreendimentos tendem a formar verdadeiras redes de negócios, formais ou informais. Essas redes atuam de modo a definir, de forma durável, as ações coletivas e os mecanismos que assegurem, ao menor custo, que o comportamento individual dos parceiros siga as regras estabelecidas para as ações coletivas (SAUVÉE, 2001).

A cooperação interorganizacional consiste numa maneira de reduzir incertezas e minimizar riscos dos agentes envolvidos no agronegócio. A cooperação entre diferentes indivíduos ou organizações pode promover a aquisição de recursos e capacidades difíceis de serem alcançadas individualmente. Além disso, a cooperação pode contribuir para a consolidação de relacionamentos de longo prazo e para o alcance de vantagem competitiva para as organizações. Há diversas variáveis citadas na literatura, discutidas ao longo desse artigo, que podem favorecer a emergência da cooperação. Porém, essas variáveis tendem a ser analisadas isoladamente e de forma independente, desconsiderando o efeito de sua interação. Assim, buscando preencher essa lacuna, essa pesquisa propõe o desenvolvimento de um modelo sistêmico capaz de demonstrar as relações causais (interdependências) entre as variáveis de ocorrência da cooperação. Com base nas evidências empíricas, o modelo busca identificar as relações de causa e efeito entre as variáveis que favorecem o estabelecimento e manutenção das ações coletivas. Assim, é possível identificar feedbacks de reforço e de balanço entre as variáveis.

Três proposições guiaram a pesquisa: P1: É possível identificar condicionantes para a cooperação envolvendo produtores de pequeno porte; P2: Há uma relação causal entre as variáveis que favorecem a ocorrência das ações coletivas. Conhecer as relações de interdependência entre as variáveis consiste numa importante fonte de aprendizado e deve servir como base para o desenvolvimento de modelos mais complexos, até mesmo a simulação de cenários. Dessa forma, políticas públicas e privadas buscando auxiliar os agentes econômicos a construir relacionamentos sustentáveis que permitam ganhos compartilhados podem ser elaboradas.

\section{Revisão de literatura}

Uma rede é formada por um sistema de organizações interdependentes envolvidas nos processos de produção, distribuição e utilização de bens e serviços. Amato Neto (2000) considerou que as redes são temas centrais na teoria organizacional, consistindo numa maneira de regular a interdependência dos sistemas complementares, como produção, pesquisa, engenharia e coordenação, de forma diferente do que agregá-los numa única firma. Pode ser adicionada a essa definição a regulação da interdependência entre firmas da mesma área de competência, que passam a cooperar ao invés de competir.

Claro (2004), com base em revisão de literatura, reportou a existência de dois níveis de análise na teoria de redes, o nível individual e organizacional. $\mathrm{O}$ nível individual está relacionado, principalmente, ao capital social e ao capital humano. O capital humano está associado às habilidades individuais, enquanto o capital social está associado às oportunidades. Já o nível organizacional está relacionado às alianças, gestão da organização, aprendizado, estratégia e canais de distribuição.

Os relacionamentos dentro das redes podem aumentar o capital social de uma empresa, por meio do acesso à informação, know-how tecnológico e suporte financeiro. Além disso, esses relacionamentos contribuem para a responsabilidade social à medida que desencorajam os agentes a se relacionarem com outras firmas fora da rede e reduzem custos de 
coordenação entre eles (OMTA; TRIENEKENS; BEERS, 2001).

Nohia e Eccles (1992) descreveram as redes como uma base estrutural para a cooperação. Pequenos empreendimentos poderiam se tornar mais competitivos à medida que as redes podem ser usadas para conferir flexibilidade ao setor, estimular a inovação, maximizar a resolução de problemas. Claro (2004) analisou o efeito da estrutura organizacional em rede sobre os relacionamentos entre fornecedorcomprador dentro do canal de distribuição e concluiu que a informação é o efeito positivo central gerado pela estrutura. Dessa forma, os relacionamentos dentro do canal são beneficiados à medida que a coordenação de processos e atividades é facilitada. Isso permite a formação e manutenção da ação coletiva, a realização de investimentos específicos à transação, a confiança e a colaboração. Podem ser considerados três tipos de impactos associados à consolidação dos arranjos das redes: impactos associados à cooperação técnico-produtiva, que estão relacionados ao aumento da eficiência operacional (decorrente de economias técnicas e de custos de produção e de transação) e à flexibilidade produtiva; impactos associados à cooperação interorganizacional que afetam decisões produtivas e tecnológicas dos agentes inseridos na rede; e os impactos associados à cooperação tecnológica, que estão relacionados com a troca de informações e ao potencial inovativo dos agentes que compõem a rede (BRITTO, 2002). Devem ser destacadas também as decisões estratégicas, mais difíceis de serem compartilhadas devido às diferenças em termos de cultura organizacional e por consistirem em fontes de vantagens competitivas para as organizações.

Aspectos institucionais, sociais e culturais interferem na formação e formato das redes (GRANDORI; SODA, 1995). O primeiro fator aponta para os aspectos institucionais como condicionantes da eficácia e facilidade na formação da rede. O segundo aspecto parte do pressuposto de que existe um relacionamento social antes do estabelecimento de qualquer relacionamento de troca entre as organizações. Assim, elementos de coordenação social, como informação e comunicação, compõem a base para mecanismos mais elaborados de coordenação interfirma. Os aspectos culturais, por sua vez, estão relacionados à cultura organizacional da firma. Outros fatores sociais que contribuem para a formação e manutenção de relacionamentos cooperativos dentro das redes são as crenças, atitudes, heterogeneidade dos grupos (incluindo questões de gênero), valores e objetivos dos agentes envolvidos.

A literatura aponta para o tamanho e heterogeneidade dos grupos como fatores que interferem no desempenho da ação coletiva (OLSON, 2001; NASSAR; ZYLBERSTAJN, 2004). Quanto maiores e mais heterogêneos são os grupos, maior é a possibilidade de surgimento dos free-riders e de assimetria de poder. Para evitar tais barreiras à cooperação, são necessários mecanismos de incentivo para que os indivíduos participem da ação coletiva. Entretanto, Matopoulus, Vlachopoulou e Manthou (2007) identificaram que a assimetria de poder, por exemplo, não é uma barreira à cooperação se o agente mais fraco é capaz de gerar habilidades únicas.

Destaca-se que uma ação coletiva, ou seja, cooperação horizontal e vertical, é formada por grupos de atores que estão ligados por diferentes razões que podem ser de ordem financeira, fatores tecnológicos e recursos humanos, entre outras. A cooperação surge quando os agentes reconhecem que não são capazes de resolver problemas nem atingir resultados desejados de forma isolada. No entanto, é importante ressaltar que os interesses são influenciados não somente por motivos econômicos, mas também motivos sociais e políticos (BRITO, 2001). As ações coletivas têm como objetivos: o acesso a outra dimensão de bem-estar material; modificar as relações sociais e de poder existentes no interior de populações específicas; influenciar as políticas públicas para ampliar as possibilidades de desenvolvimento e superar a exclusão; desenvolver a capacidade dos indivíduos (capital humano); fortalecer as organizações; e aprofundar normas e valores como a solidariedade, reciprocidade e confiança, que contribuem para o bem comum (capital social) (RAMÍREZ; BERDEGUÉ, 2003). Entretanto, na maioria das vezes, os benefícios coletivos são insuficientes para motivar a contribuição individual. Existem interesses individuais que podem diferir dos interesses do grupo, surgindo, assim, conflitos e dificuldades de se estabelecerem as estratégias coletivas. Os indivíduos não tendem a se comportar de maneira racional para atingir os objetivos comuns do grupo a não ser que haja mecanismos de incentivo. Esses mecanismos servem como motivação para a contribuição individual na ação coletiva, os quais podem ser incentivos monetários ou sociais (OLSON, 2001).

Barreiras à ação coletiva também podem surgir quando os membros são livres para escolher se contribuem ou não para alcançar os objetivos comuns. Nesse caso, os indivíduos podem ser induzidos a não colaborar para a ação coletiva, pois eles poderão se beneficiar da ação sem incorrer no ônus para alcançar os objetivos. Esse indivíduo, ou firma, é conhecido como carona ou free-rider.

Ring e Van de Ven (1994) esclareceram que, para entender os relacionamentos cooperativos interorganizacionais, é necessário entender também o comportamento dos indivíduos, ou firmas, individualmente. Percebe-se que os relacionamentos geralmente são iniciados a partir de acordos informais, de pouca abrangência e pouco risco envolvido. A partir daí, à medida que o relacionamento é estabelecido e 
atende a critérios de eficiência e equidade, as partes se sentem seguras para estabelecer vínculos mais próximos. A equidade pode ser entendida como a distribuição de benefícios, de forma igualitária, para os indivíduos dentro de um grupo. Ela interfere na cooperação entre os indivíduos, pois afeta a coesão dos grupos. Outro fator que contribui para a coesão dos grupos é o alinhamento entre os interesses coletivos e individuais. Brito (2001) considerou que a tensão entre os interesses coletivos e individuais é o elemento-chave para entender a emergência de formas coletivas de organização, bem como seu impacto no desenho das redes. Na ausência de mecanismos de incentivo e controle, podem surgir desde oportunismo (free-rider) até conflitos relacionados com a disputa de poder e com a distribuição equitativa dos benefícios, que irão interferir no desempenho da ação coletiva.

A informação é tida como principal externalidade gerada pela estrutura organizacional na forma de rede, beneficiando os relacionamentos interorganizacionais (CLARO, 2004). Em um relacionamento cooperativo, a troca de informações é fundamental para a manutenção da cooperação. À medida que se conhecem as necessidades dos clientes, desejos, planos de negócios e investimentos, é conferida uma vantagem competitiva para os parceiros. Entretanto, se a confiança não estiver presente, o relacionamento não se mostra sustentável (ZINELDIN; JONSSON, 2000). A confiança e a reciprocidade ajudam a melhorar a estrutura social, favorecendo os relacionamentos cooperativos entre os agentes já que a confiança é considerada uma característica das relações sociais (SABEL, 1993).

Matopoulus, Vlachopoulou e Manthou (2007) identificaram dois pontos principais para analisar a cooperação dentro de cadeias de suprimentos. O primeiro está relacionado com o desenho e o gerenciamento da cooperação, determinando a intensidade com que ela ocorre. $\mathrm{O}$ segundo ponto identifica variáveis que levam ao estabelecimento e à manutenção da cooperação nos relacionamentos, como poder, dependência mútua, confiança e o compartilhamento de riscos e recompensas. Analisando cadeias agroalimentares, os autores identificaram que, devido à complexidade e heterogeneidade ao setor, as variáveis do segundo ponto são mais relevantes para a cooperação entre os agentes.

De acordo com Batt (2003), no caso da distribuição de FLV, em que os preços são formados pela oferta e demanda dos produtos no mercado, há um elevado nível de incerteza para o produtor rural. Para minimizar essas incertezas, os agentes do mercado (clientes) tendem a realizar investimentos específicos à transação e compartilhar informações, como previsão de demanda e características desejadas dos produtos, com seus fornecedores. Assim, é estabelecida uma confiança entre os agentes, sinalizando um relacionamento de longo prazo. De acordo com esse autor, o compartilhamento de informações de mercado não irá apenas melhorar a transparência na transação, mas sinalizar o desejo de os agentes estabelecerem relacionamentos cooperativos.

Para Brito (2001), as redes tendem a ser estáveis devido às ligações constituídas e consolidadas entre os agentes que a formam. O custo envolvido na constituição de novos relacionamentos favorece, assim, o estabelecimento de ligações estáveis. No entanto, esse autor considerou que as redes são estruturas "vivas" à medida que os atores, as atividades e os recursos estão continuamente mudando devido à dinâmica do processo econômico e ao relacionamento entre os atores, que buscam aumentar seu controle sobre as atividades, os recursos e sobre os outros atores.

A estrutura em rede oferece oportunidades e limitações às empresas. O desempenho de uma empresa resulta da inter-relação entre ela e os agentes que compõem sua rede e do investimento feito por todos os envolvidos. Quanto mais forte o relacionamento entre os agentes, maior tendem a ser os benefícios. Por outro lado, as empresas são menos livres para realizar mudanças e ajustes individuais (HAKANSSON; FORD, 2002). As associações de longo prazo podem até mesmo levar à estagnação (SMITH-DOER; POWELL, 2005). Se os relacionamentos entre os agentes são muito rígidos, os benefícios das redes podem ser anulados, pois a flexibilidade é necessária para ajustes mútuos e dinâmicos.

Os canais de distribuição consistem em organizações interdependentes, envolvidas no processo de tornar um produto ou serviço disponível para uso e consumo (STERN; EL-ANSARY; COUGHLAN, 1996). Os canais de distribuição não devem apenas satisfazer a demanda, por meio do fornecimento de mercadorias e serviços no lugar, na quantidade, qualidade e preços adequados, mas devem também estimular a demanda por meio de atividades promocionais. Os canais de distribuição consistem num sistema devido à relação de interdependência entre os agentes que 0 compõem, ou seja, os componentes do canal mantêm inter-relações de forma interdependente, com o objetivo de produzir um resultado específico. Essa definição engloba vários aspectos relacionados com os canais, a exemplo da relação de interdependência entre os agentes envolvidos no processo e a necessidade de coordenação entre os agentes para atender às necessidades do consumidor final.

\section{Método}

De acordo com o problema a ser estudado e o objetivo proposto, foi adotada uma estrutura metodológica que se mostrou mais adequada. Concluiu-se que esta é uma pesquisa descritiva, em que o método de coleta de dados é qualitativo. A 
pesquisa descritiva considera que todos os dados da realidade são importantes e devem ser examinados.

A estrutura metodológica propõe a análise das ações coletivas baseadas na cooperação, com o objetivo de identificar variáveis relevantes no estabelecimento e manutenção das ações coletivas, bem como analisar o efeito de sua interação, ou seja, as relações de causa e efeito entre elas. As unidades de análise foram agentes do canal de distribuição de diferentes organizações (formais ou informais) que adotavam ações coletivas na comercialização de FLV. Essas organizações estavam inseridas, ou não, em clusters regionais, ou arranjos produtivos locais, ou em polos de produção. Os casos estavam organizados em associações, cooperativas ou mesmo em grupos informais.

A existência de cooperação horizontal e vertical (formal ou informal) entre produtores e outros agentes envolvidos no processo de distribuição foi o critério para a seleção dos casos analisados. Foram desenvolvidos quatro roteiros de entrevistas dirigidos para cada agente a ser entrevistado: responsável pela gestão da organização; produtor rural que fazia parte da organização; cliente que mantinha relacionamento cooperativo; e instituição colaboradora, quando existente.

Foram selecionados somente casos de sucesso para a análise. Essa escolha é justificada pela busca de identificação de variáveis relevantes na construção de ações coletivas na comercialização de FLV. A utilização desses casos propiciou a execução da pesquisa no tempo proposto e com os recursos disponíveis. Dessa forma, foram selecionados casos em que havia cooperação horizontal entre produtores de FLV (associações, cooperativas e grupos informais), bem como agentes do canal de distribuição com quem os grupos mantinham parcerias (relacionamentos mais próximos). Estes consistiram em supermercados, atacadistas e agroindústrias.

Foram realizados dois casos para cada região brasileira, totalizando 10 estudos de caso. Todos os agentes foram escolhidos de forma intencional, não probabilística, atendendo a critérios que tiveram relevância para o problema estudado e que foram definidos com base nos dados secundários. A escolha dos casos foi baseada em: 1) referências encontradas nos dados secundários pesquisados; 2) dados divulgados por associações e órgãos representativos do setor; 3) sugestão de pares por empresas envolvidas em ações coletivas relacionadas à comercialização de FLV; e 4) pesquisadores, provenientes de instituições públicas e privadas, ligados ao tema em questão. Além disso, foi feita uma exaustiva busca por casos que se aplicavam às exigências em instituições de pesquisa e extensão como: Empresa Brasileira de Pesquisa Agropecuária (Embrapa), em especial o Centro de Pesquisa em Mandioca e Fruticultura, o Centro Nacional de Pesquisas de Hortaliças, a
Embrapa Semi-Árido e a Embrapa Amazônia Oriental; Ministério do Desenvolvimento Agrário (MDA), em especial o Programa de Promoção em Igualdade em Gênero, Raça e Etnia; Empresa de Assistência Técnica e Extensão Rural (Emater) do Distrito Federal, do Pará e de Rondônia; Serviço de Apoio à Pequena e Média Empresa (SEBRAE), em especial o SEBRAE/SP, SEBRAE/RR, SEBRAE/PA; Instituto de Desenvolvimento Agrário, Assistência Técnica e Extensão Rural de Mato Grosso do Sul (IDATERRA); Universidade Federal do Mato Grosso do Sul (UFMS); Universidade de Brasília (UNB); Secretaria do Desenvolvimento Agrário do Mato Grosso do Sul; Agência Rural - Goiás; Universidade Federal de Pernambuco; Empresa Baiana de Desenvolvimento Agrícola S.A. (EBDA); Brazilian Grape Market Board (BGMB); Organização das Cooperativas Brasileiras (OCB); Organização Internacional Agropecuária (OIA/Brasil).

$\mathrm{Na}$ amostra foram identificados diversos casos e considerados aqueles que mantiveram as exigências de seleção no momento da pesquisa e que foram considerados casos de sucesso. Ao todo foram realizadas 33 entrevistas pessoais, em todas as regiões do Brasil, no período de novembro de 2004 a abril de 2005. Buscou-se analisar dois estudos de caso para cada região brasileira, de forma a possibilitar a compreensão das variáveis que influenciaram a cooperação em grupos inseridos em diferentes ambientes institucionais formais e informais. A partir daí foi possível a identificação de pontos comuns entre os casos e a elaboração de um modelo sistêmico.

Após a identificação dos casos de sucesso foi realizada uma análise de pares. Esse tipo de análise permitiu uma visão precisa dos condicionantes dos esforços coletivos. Além disso, a análise de pares envolvendo produtores, das organizações nas quais estão inseridos, de agentes colaboradores do canal de distribuição e de instituições de apoio permitiu avaliar o relacionamento de forma mais clara, já que era esperado certo grau de dificuldade de obtenção de dados considerados estratégicos pelas empresas. As entrevistas foram orientadas por diferentes roteiros, dirigidos para cada agente a ser entrevistado: responsável pela gestão dos grupos de produtores; produtores rurais que faziam parte desses grupos; cliente com quem os grupos mantinham relacionamento cooperativo; e instituições de apoio, quando presentes.

Este artigo consiste num recorte descritivo de uma pesquisa mais ampla cujo objetivo foi determinar os condicionantes para a inserção de pequenos produtores rurais no processo de fornecimento de produtos a importantes canais de distribuição de FLV. Para a consecução deste objetivo, diversas variáveis foram identificadas a partir da teoria consultada (OLIVER, 1990; OSTROM, 1990; 
BAKER, 1992; BRASS; BURKHARDT, 1992; HAKANSSON, 1992; HEIDE, 1994; DYER, 1997; COLEMAN, 1998; ZAHEER; McEVILY; PERRONE, 1998; ALTERBURG; MEYER-STAMER, 1999; AMATO NETO, 2000; HUMPHREY; OETERO, 2000; MURDOCH, 2000; ZINELDI; JONSSON, 2000; OLSON, 2001; FUTEMMA et al. 2002; HARDMAN; DARROCH; ORTMANN, 2002; BATT, 2003; KOTZAB; TELLER, 2003;BOHMAN; BOTER; TESAR, 2004; CLARO, 2004; GRANDORI; SODA, 1995; BURGER; KAMEO; SANDEE, 2005; Chiriboga, 2007; SEPPANEN; BLOMQVIST; SUNDQVIST, 2007; SHEPHERD, 2007). Estas foram agrupadas em diferentes categorias: A partir da revisão dessa literatura, buscou-se separar as variáveis em grupos (Figura 1). Identificaram-se então seis categorias de variáveis. As três primeiras categorias dão suporte ao surgimento e à manutenção da cooperação: 1) As variáveis organizacionais aquelas que influenciam a organização e sua estrutura, como o tipo de organização (nível de complexidade), estrutura organizacional, nível de formalização e existência de parcerias; 2) As variáveis tecnológicas aquelas relacionadas à tecnologia utilizada para suportar a cooperação como o nível de sofisticação tecnológica e o nível de investimento em tecnologia; 3) As variáveis institucionais - aquelas provenientes do ambiente externo, principalmente governamentais, que desenhavam o ambiente e influenciavam o comportamento dos agentes e, consequentemente, a cooperação, como a existência de sistemas de regulação, os programas especiais e o suporte do governo por meio de políticas públicas.

As outras variáveis influenciam tanto a cooperação horizontal quanto a vertical: 4) Variáveis sociais aquelas que analisam fatores de ordem social que interferem na cooperação, por exemplo, questões étnicas como um fator primordial que levou um determinado grupo de produtores a confiarem uns nos outros e a iniciarem ações coletivas; ou o capital social, que consiste em valores, normas e relacionamentos compartilhados e resultam, por exemplo, de trajetórias comuns a um grupo e que influenciam a cooperação; 5) Variáveis gerenciais - aquelas que influenciam no gerenciamento da cooperação como o planejamento, o fluxo de informação, a qualidade entre outros; e 6) Variáveis econômicas - aquelas que influenciam nas decisões econômicas dos agentes
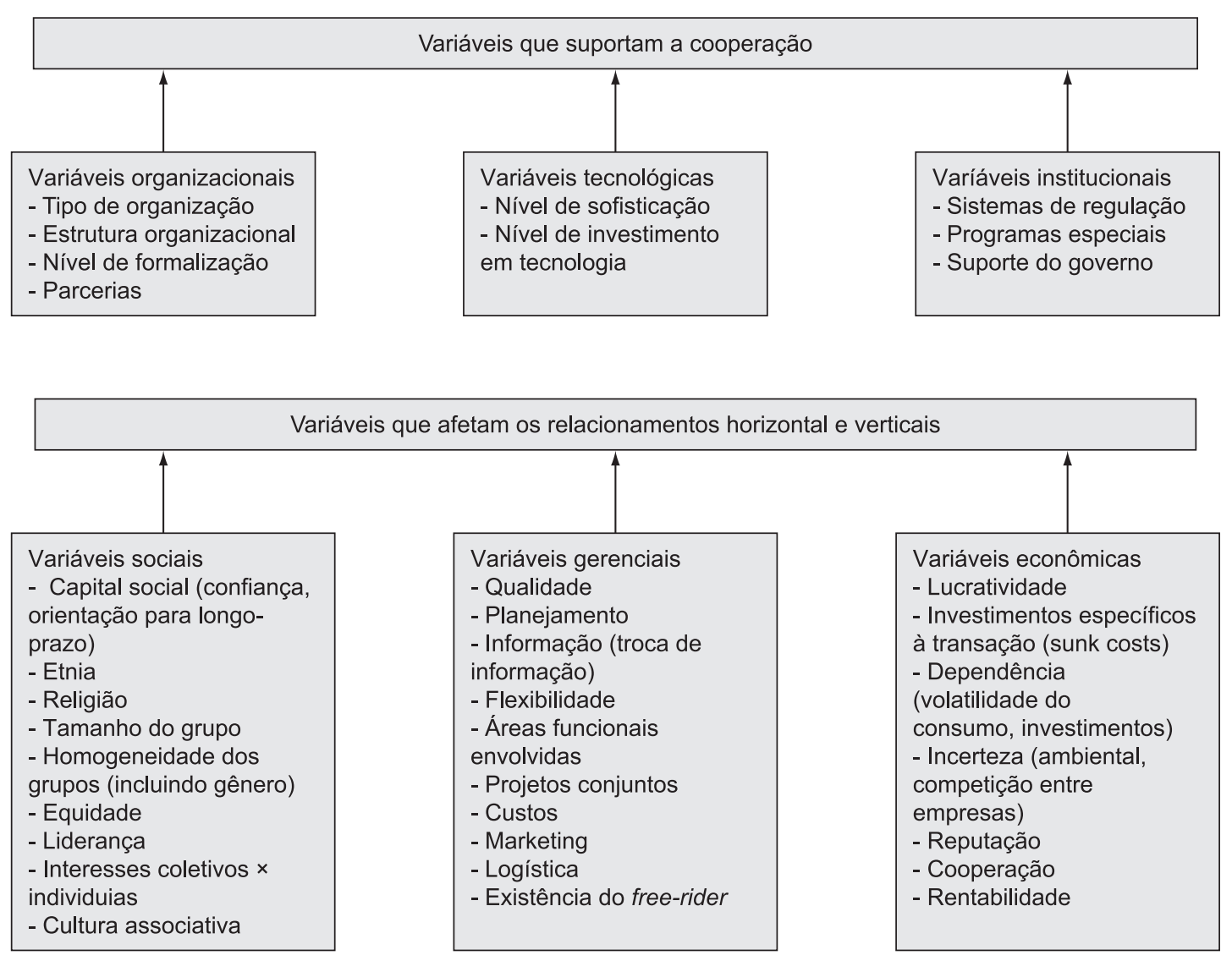

Figura 1. Variáveis que suportam a cooperação e que afetam a cooperação horizontal e vertical. Fonte: elaborado pelos autores. 
tanto individualmente quanto dos grupos, como a lucratividade, os investimentos específicos à transação (sunk costs), a especificidade dos ativos; a incerteza existente nas transações, a frequência, entre outros.

As variáveis foram utilizadas para a construção dos roteiros de entrevistas. A partir daí, com base na pesquisa empírica, foi feita a identificação das variáveis que, de fato, influenciavam o estabelecimento e manutenção das ações coletivas. Essa análise foi feita com base na Análise de Conteúdo das entrevistas. De acordo com Bardin (2008, p. 44)

\section{[...] é um conjunto de técnicas para análise das comunicações, visando obter, por procedimentos sistemáticos e objetivos de descrição do conteúdo das mensagens, indicadores (quantitativos ou não) que permitam a inferência de conhecimentos relativos às condições de produção/recepção (variáveis inferidas) destas mensagens [...].}

Ela é particularmente útil, pois nesta pesquisa transcreveram-se as entrevistas e as discussões com especialistas. A técnica permitiu a identificação da ideia por respondente, sendo observada a ênfase dada a cada resposta durante as entrevistas. A frequência de repetição das respostas também foi parte do processo de análise. A análise de conteúdo permitiu, nesta pesquisa, analisar em profundidade uma informação a partir do comportamento, opiniões e ideias, apresentadas na forma verbal ou escrita.

Na medida em que foi observado um padrão de recorrência na relação entre as variáveis a partir dos diagramas desenvolvidos para cada caso, foi possível o desenvolvimento de um modelo sistêmico genérico. O modelo consiste num diagrama de loop causal que permite a visualização das inter-relações entre as variáveis consideradas relevantes no estabelecimento e manutenção da ação coletiva.

\section{Discussão dos resultados}

Para cada estudo de caso realizado foi elaborado um modelo de causa e efeito, contendo as principais variáveis que influenciaram no processo de cooperação. Com base na análise dos dados, verificou-se que as variáveis que contribuem para o estabelecimento das ações coletivas verticais e horizontais entre agentes do setor de FLV estão relacionadas.

Percebeu-se a existência de um padrão de interrelação entre as variáveis nos casos analisados. Assim, foi possível desenvolver um modelo genérico capaz de demonstrar as relações causais entre as principais variáveis que contribuíram para a ação coletiva. Ressalta-se que, em favor da maior simplificação do modelo visando facilitar o seu entendimento, foram desconsideradas especificidades pontuais de cada caso.

O modelo proposto consiste num diagrama de loop causal, ou seja, uma representação gráfica que permite a exploração das inter-relações dinâmicas entre as variáveis, assim como testar hipóteses sobre o problema. Os loops são definidos como sistemas formados por fluxos de realimentação. Segundo Forrester (1961), um sistema de realimentação de informação existe sempre que um ambiente leva para uma decisão que resulta em uma ação, na qual afeta o ambiente e, desse modo, influencia decisões futuras. Os diagramas de loop causal são compostos por loops de reforço e loops de equilíbrio, por relações de causa e efeito entre as variáveis e por defasagens de tempo (delays) entre a causa e o efeito (representados por barras paralelas). De acordo com Anderson e Johnson (1997), os loops podem ser definidos como uma sequência de efeitos mútuos de causa e efeito. São caracterizados por serem catalisadores de mudanças no comportamento do sistema. As ligações entre cada variável demonstram como elas estão interligadas, e o sinal "+" ou "--" indica como uma variável afeta a outra. O sinal "+" representa uma relação direta entre as variáveis, ou seja, na mesma direção. Já o sinal "_" representa uma relação inversa, ou seja, na direção contrária.

Os loops de reforço têm a característica de ampliar os efeitos de uma variável sobre a outra em uma direção, isto é, a mudança em uma variável vai provocar mudança de forma mais intensa na variável relacionada. Podem ser ciclos virtuosos ou ciclos viciosos, dependendo do impacto da mudança. São representados pela letra "R". Já os loops de equilíbrio são aqueles que estabilizam o sistema, anulando o efeito de uma variável sobre a outra, buscando trazer o sistema ao equilíbrio. São representados pela letra "B".

O número de relações "-_" existentes em um loop define seu caráter de reforço ou de equilíbrio. Números pares de relações negativas caracterizam um loop de reforço, enquanto números ímpares de relações negativas caracterizam um loop de equilíbrio. É importante ressaltar que é a combinação de loops de reforço e de equilíbrio que configura o caráter sistêmico da estrutura.

Outro ponto importante a ser considerado é a existência de defasagens de tempo entre a causa e efeito na relação entre as variáveis. Frequentemente, as consequências das ações demoram longo tempo para serem percebidas, assim, existe uma defasagem de tempo entre a percepção dos resultados, a decisão acerca das soluções e a sua implementação. A percepção da existência de defasagens de tempo na relação entre as variáveis é muito importante porque elas podem conferir um comportamento imprevisível do sistema.

O modelo sistêmico (Figura 5) está apresentado em partes de forma a facilitar seu entendimento (Figuras 2,3,4,5 e 6). O ponto de partida do diagrama sistêmico genérico é o acesso a canais de comercialização, que se traduz no acesso a canais mais 
rentáveis. Esse ponto foi considerado como central, pois consiste na principal razão para a formação dos grupos e estabelecimento da ação coletiva. A partir desse ponto, as variáveis devem ser analisadas aos pares, observando-se o tipo de relação que existe entre elas ("+" ou "--") e o caráter dos loops formados ("R" or "B").

A análise da primeira parte do modelo sistêmico (Figura 2) revela que o nível de exigência desejado pelo cliente consiste num ponto crucial para o acesso ao canal (transação). O nível de exigência está relacionado, principalmente, com as especificidades dos ativos, como a qualidade exigida, a quantidade demandada, a diversidade de produtos e a regularidade no fornecimento. É a diferença entre o nível de exigências demandado pelo cliente e o nível ofertado pelo fornecedor que influencia o acesso ao canal. Ou seja, quanto maior a diferença entre o nível de exigências demandado e a capacidade dos produtores em atender às especificações, maior a dificuldade de acesso aos canais.

Quanto maior o nível de exigências por parte do cliente, maior será o nível de especificidade dos ativos demandados, caso o nível de exigências seja superior às dos outros clientes. Nesse caso, a especificidade implica realização de investimentos específicos à transação por ambas as partes. Implica também maiores custos relacionados à interrupção do relacionamento. Os custos relacionados com a interrupção da transação, juntamente com a possibilidade de oportunismo dos agentes, conferem incerteza em relação à transação. Nesse sentido, a existência dessa incerteza influencia negativamente o acesso ao canal. Em outras palavras, a desconfiança quanto ao comportamento futuro do outro consiste em uma barreira no desenvolvimento do relacionamento - acesso ao canal.

$\mathrm{Na}$ Figura 2, demonstra-se que os riscos relacionados com a incerteza da transação podem ser amenizados ou anulados por meio do estabelecimento de mecanismos de incentivo, como o pagamento de preços-prêmio, compartilhamento de informações e planejamento conjunto das atividades, entre outros. A análise do diagrama sistêmico indica que a necessidade de mecanismos de incentivo é o fator gerador da colaboração vertical, pois aumenta o comprometimento de ambas as partes, com a continuidade da transação.

À medida que a cooperação vertical é desenvolvida, existe uma tendência de diminuição da assimetria de informações. Os mecanismos de incentivo utilizados para operacionalizar a cooperação vertical resultam na diminuição das possibilidades de oportunismo, reduzindo as incertezas da transação e possibilitando o acesso ao canal.

De acordo com a Figura 2, uma vez ocorrido o acesso ao canal, a recorrência (frequência) das transações contribui para a construção da reputação dos agentes. Ao longo do tempo, a reputação colabora para o aumento da confiança e, consequentemente, a diminuição das incertezas. A evidência empírica reforça a afirmação de autores como Seppanen, Blomqvist e Sundqvist (2007) e Forrester (1961) de que a confiança é um conceito recíproco, sendo em parte a causa e o efeito. Isto é, a confiança não deve ser considerada como uma variável numa relação causal direta, mas passível de sofrer influência e influenciar outras variáveis. Assim, a pesquisa empírica revelou que, apesar de não ser uma relação direta, a confiança foi um fator recorrente para justificar o acesso ao canal.

A análise da Figura 3 revela que, quanto maior a diferença entre as exigências desejadas pelo cliente e a capacidade de atendê-las por parte dos fornecedores, maior a necessidade de investimentos em tecnologia e no planejamento da produção. O investimento em tecnologia é uma decisão gerencial que depende da disponibilidade de recursos financeiros, sejam eles próprios ou provenientes de fontes externas (Apoio Financeiro Institucional).

Existe uma defasagem de tempo entre a realização do investimento e a percepção dos resultados. No caso do modelo sistêmico proposto, existe um intervalo de tempo entre a mudança tecnológica e a melhoria no atendimento das exigências do cliente.

$\mathrm{Na}$ Figura 4, demonstra-se que a melhoria no planejamento da produção é influenciada pela cooperação vertical, pois informações como previsão de demanda e programação de plantio e colheita são compartilhadas, sustentando seus processos de tomada de decisão. Nos casos em que o apoio técnico institucional está presente, os avanços no nível tecnológico e no planejamento da produção são evidentes.

O planejamento da produção e o nível tecnológico adotados também são influenciados pela organização e pela cooperação horizontal. A variável organização e cooperação horizontal consiste no relacionamento mais próximo entre os agentes do mesmo nível, no caso a organização de produtores rurais. Com base na pesquisa empírica, verificou-se que essa cooperação propicia benefícios difíceis de serem alcançados de forma isolada. O planejamento da produção, por exemplo, envolve diversas decisões gerenciais quanto ao produto e quanto ao sistema produtivo. Quando um grupo pretende atender a uma rede de supermercados que apresenta demanda por produtos durante todo o ano é necessário que esse grupo se organize para planejar épocas de plantio visando à colheita escalonada ao longo do ano. O planejamento também permite alcançar as quantidades mínimas exigidas e a diversidade de produtos demandada e atender aos padrões exigidos. Esse nível de planejamento é dificilmente alcançado por pequenos produtores de forma isolada. A pesquisa empírica revelou casos em que os pequenos produtores 
não eram capazes de distribuir seus produtos por meio de diferentes canais, porque a quantidade colhida era pequena, o que tornava o custo de transporte inviável. Dessa forma, individualmente os produtores somente comercializavam por meio de intermediários, que buscavam os produtos na propriedade.

Considerando o nível tecnológico, observou-se que a realização de investimentos elevados, como a construção e manutenção de estruturas de packinghouse, só é possível porque os custos do investimento são diluídos entre um grupo de produtores. As dificuldades de acesso ao crédito e a aversão ao risco, entre outras, são razões pelas quais os pequenos produtores, individualmente, apresentam baixa capacidade de investimento.
A organização e cooperação horizontal é uma variável que afeta positivamente o poder de negociação do grupo devido ao conhecimento acumulado. $\mathrm{O}$ estoque de conhecimento é alimentado pelas experiências individuais de cada produtor. O conhecimento, juntamente com o apoio gerencial fornecido por instituições públicas e privadas, resulta num maior poder de negociação do grupo. Ou seja, maior possibilidade de acesso a canais mais rentáveis.

Uma vez estabelecido o acesso ao canal, bem como a cooperação vertical, observou-se que a rentabilidade da transação, ou seja, o preço pago ao grupo foi a variável responsável pela realimentação do sistema (Figura 5). No entanto, os preços não são crescentes à medida que a transação se repete. Existe

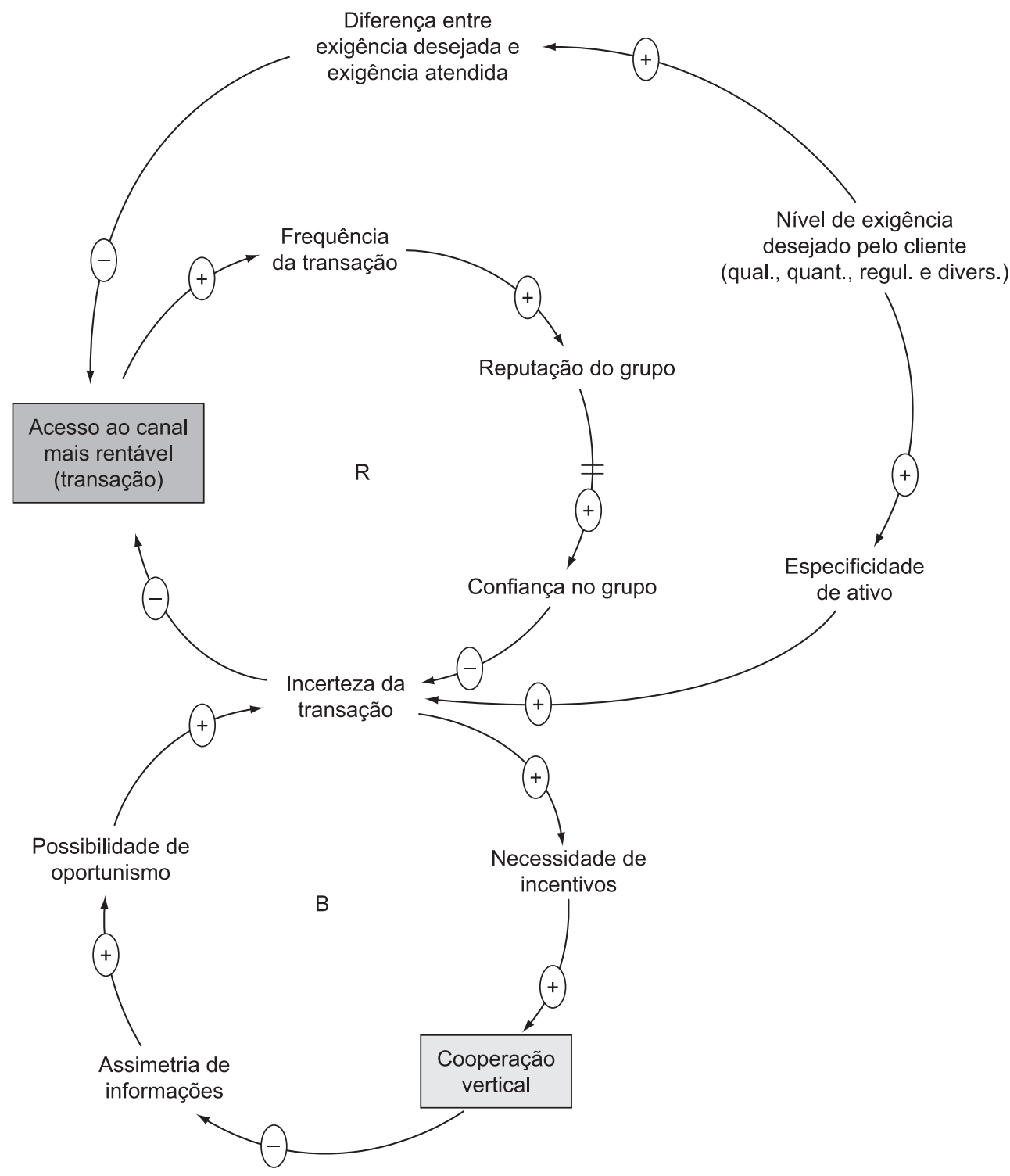

Figura 2. Modelo sistêmico - Parte 1. 
um limite para o aumento dos preços que é o poder de mercado do cliente. Quanto menor o poder de mercado, maiores tendem a ser os preços pagos aos fornecedores. Observou-se que a margem de lucro do cliente, resultante do seu poder de mercado, oscila em situações de variação de oferta e de demanda dos produtos no mercado.

A análise do modelo revela que a rentabilidade das transações influencia inversamente o estoque de possibilidade de ganho do grupo. Ou seja, quanto maior a rentabilidade, menor tende a ser o estoque de possibilidade de ganho do fornecedor, pois, como citado anteriormente, existe um limite para o comportamento dos preços. Entretanto, as possibilidades de ganho influenciam positivamente o interesse individual dos produtores em continuar participando do grupo, isto é, dar continuidade à transação. Quanto mais comprometidos com o grupo, menores são as chances dos produtores se comportarem de forma oportunista.

$\mathrm{O}$ interesse individual em participar desse relacionamento, isto é, dessa transação, contribui para o

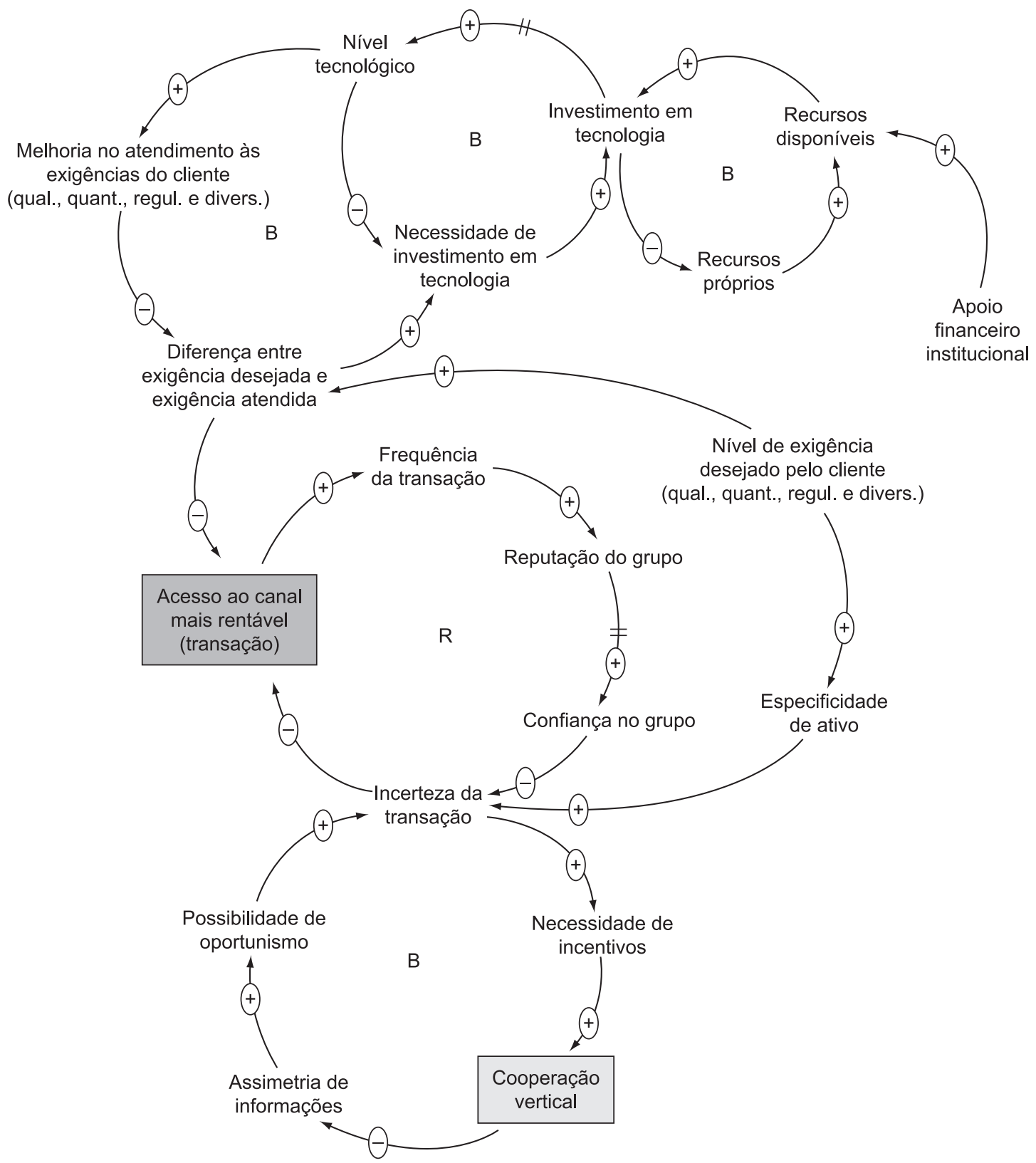

Figura 3. Modelo sistêmico - Parte $1+2$. 
fortalecimento do interesse coletivo. Isso acontece porque os produtores têm objetivos comuns para serem alcançados. Ressalta-se que o interesse coletivo é um aspecto importante para a construção do capital social, pois mantém alinhados os interesses dos indivíduos e do grupo. A pesquisa empírica revelou que a unidade étnica foi um fator externo que conferiu um nível inicial de coesão e alinhamento de interesses (capital social) superior àqueles que não apresentam esse tipo de fator.

Quanto maior o capital social de um grupo, maior tende a ser a equidade de benefícios entre os indivíduos que o compõem e, consequentemente, menor a tendência de ação dos free-riders. Dessa forma, conclui-se que a variável "interesses coletivos" afeta diretamente a organização e a cooperação horizontal.

Finalmente, percebe-se que o apoio institucional é um fator externo relevante para o estabelecimento das cooperações horizontal e vertical e para o acesso ao canal. $\mathrm{O}$ apoio institucional ocorre de diferentes formas: a) apoio técnico que influencia o planejamento da produção e o nível tecnológico adotado; b) apoio gerencial que ocorre na forma de capacitação e intermediação no relacionamento entre os agentes e influencia a capacidade de negociação do grupo, entre outros; e c) apoio financeiro, que é representado pelas agências de fomento ao crédito. $\mathrm{O}$ apoio institucional financeiro afeta os recursos disponíveis para investimento em tecnologia, por exemplo. Entretanto, ressalta-se que o apoio institucional deve evitar posturas assistencialistas e subsídios, pois essa postura não favorece o aprendizado e o desenvolvimento de relações de mercado sustentáveis à longo prazo.

A pesquisa empírica revelou que os diferentes agentes dos canais de distribuição impõem diferentes exigências no processo de aquisição de produtos. Considerando a venda de produtos para agroindústrias, as especificidades exigidas estão relacionadas a padrões de qualidade, lotes mínimos, prazos de pagamento e distância entre as unidades de produção e a planta de processamento. Considerando atacadistas e varejistas,

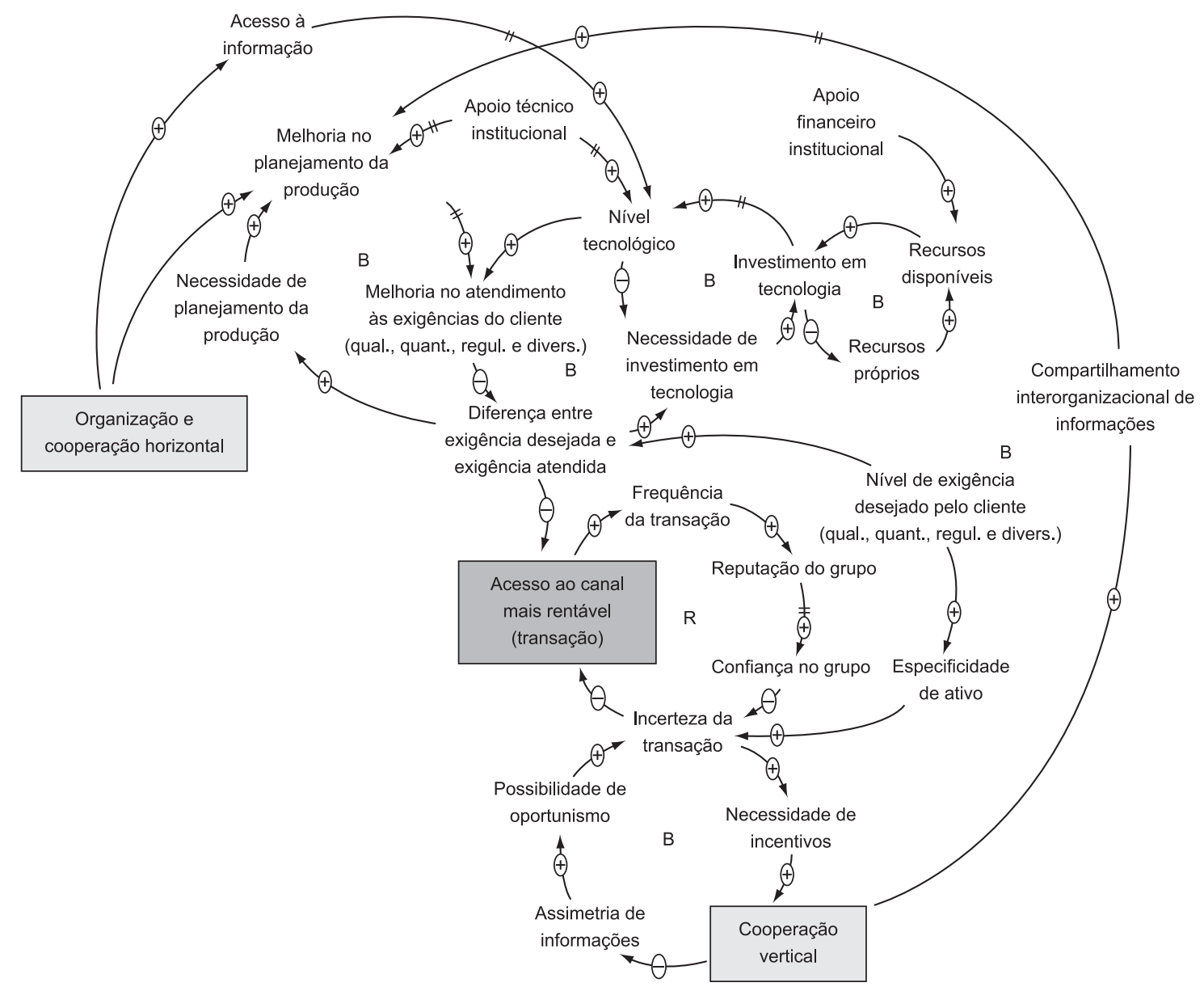

Figura 4. Modelo sistêmico - Parte $1+2+3$. 


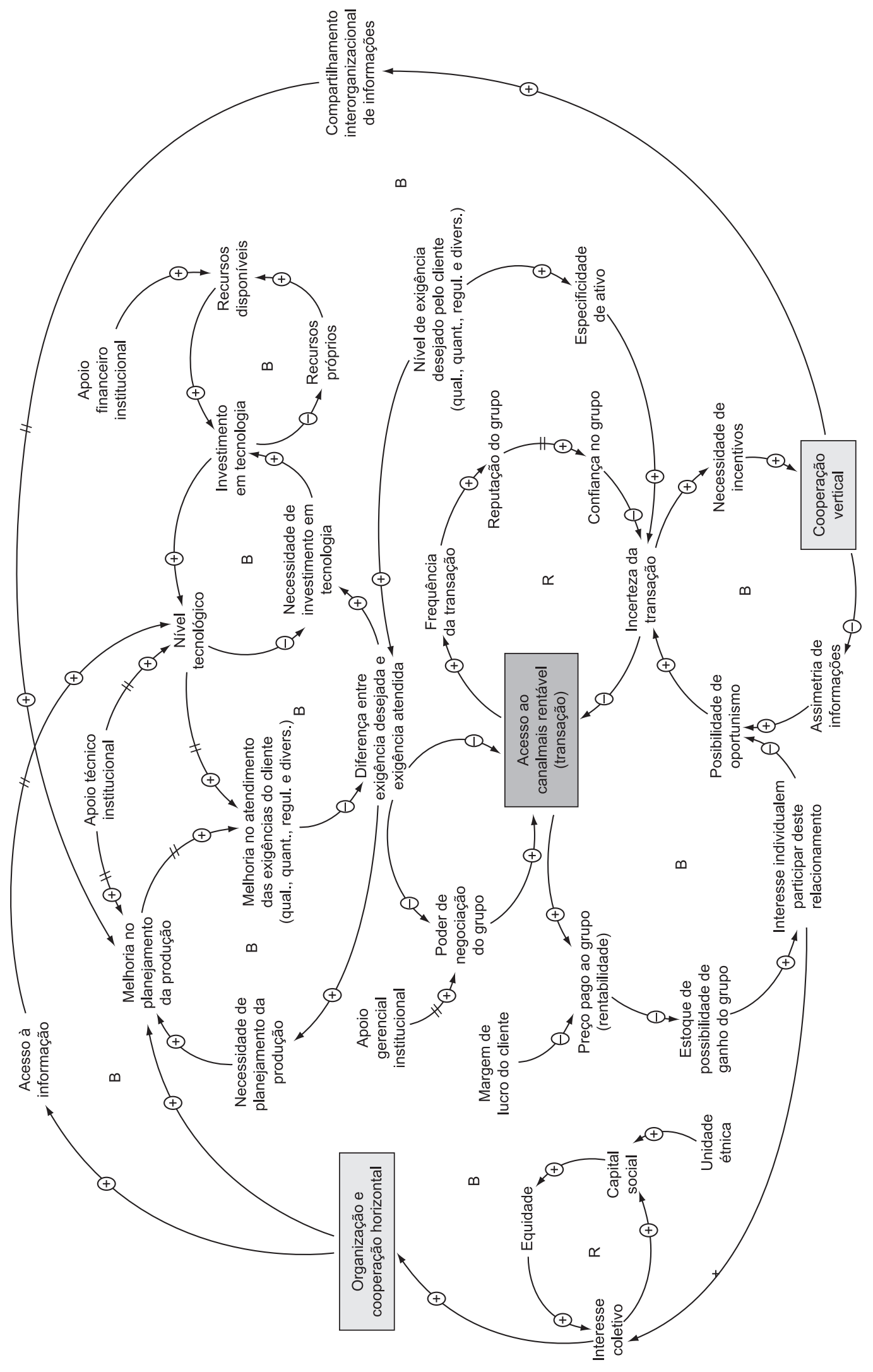


os principais requisitos para fornecimento estão relacionados à segurança do alimento, lotes mínimos, regularidade do suprimento e diversidade de produtos. Além isso, ambos agentes do canal de distribuição demandam certo nível de recursos tecnológicos e habilidades gerenciais.

Observa-se que algumas dessas exigências são difíceis de serem alcançadas individualmente por pequenos produtores devido às características inerentes à pequena propriedade rural como área reduzida, baixa escala de produção. Tais características conferem aos pequenos produtores um certo grau de dificuldade em alcançar economias de escala quando comparados à agricultura comercial (ou patronal). $\mathrm{O}$ baixo volume produzido também os desfavorece nas transações, conferindo aos produtores um baixo poder de barganha. A pesquisa empírica revelou casos em que os produtores não foram capazes de vender seus produtos para varejistas, por exemplo, pois a quantidade ofertada era baixa em relação ao preço do frete. Assim, individualmente, os produtores apenas comercializavam seus produtos por meio de intermediários que buscavam os produtos diretamente nas propriedades rurais.

Uma vez que são características inerentes à pequena propriedade rural, são difíceis de serem transpostas a menos que haja adoção intensiva de tecnologia ou a menos que os ativos sejam altamente específicos (especificidade física, temporal, locacional, entre outras). Assim, duas alternativas podem ser consideradas, o posicionamento do produto no mercado e a cooperação. A primeira alternativa consiste na agregação de valor e diferenciação de produtos para que acessem mercados de melhor remuneração. As dificuldades, nesse caso, estão relacionadas à adoção de inovação por parte dos pequenos produtores. As inovações, tanto tecnológicas quanto gerenciais, ainda não são muito difundidas entre os produtores devido ao seu custo, à resistência a mudanças e à aversão ao risco por parte dos pequenos produtores. Tal comportamento tem mudado nos últimos anos principalmente devido às políticas públicas voltadas para esse segmento. Como exemplo, podem ser citados o Programa Nacional de Fortalecimento da Agricultura Familiar (PRONAF) e os projetos de extensão fomentados pelo Conselho Nacional de Desenvolvimento Científico e Tecnológico (CNPq) fomentados pelo governo federal. No Estado de São Paulo o Sistema Agroindustrial Integrado (SAI) do SEBRAE-SP, os programas da Coordenadoria de Assistência Técnica Integral (CATI), entre outros, têm atuado no sentido de promover o desenvolvimento do agronegócio, entre eles os pequenos produtores. Humphrey (2005) destaca ainda que os pequenos produtores podem atender às demandas do mercado se tiverem habilidade, conhecimento e acesso à informação.
A segunda alternativa consiste na cooperação horizontal. Desconsiderando mercados para produtos com elevada especificidade, a cooperação se mostrou condição sine qua non para a inserção dos produtores em canais de distribuição. Sem a cooperação, as exigências em termos de quantidade, qualidade, diversidade e regularidade de oferta seriam difíceis de serem alcanças pelo produtor individualmente. A cooperação horizontal oferece condições para que os produtores atendam às exigências do canal de distribuição uma vez que promove o aumento na quantidade produzida pelo grupo, refletindo na possibilidade de economias de escala e regularidade de oferta; o aumento na diversidade de produtos, pois diferentes produtores podem aproveitar suas competências essenciais e vantagens locacionais no cultivo de diferentes produtos; e o incremento na qualidade dos produtos uma vez que a inovação e o aprendizado são mais gerados e difundidos no grupo (externalidades de rede).

A pesquisa empírica revelou que mesmo em grupos informais, em que os produtores não haviam percebido, de forma explícita, os benefícios da cooperação horizontal, eles cooperavam, de forma tácita, para acessar o canal de comercialização à medida que compartilham informações como preços pagos, técnicas de produção, inovações e potenciais clientes, além de contribuírem para minimizar custos logísticos.

Assim, percebe-se que a cooperação horizontal foi condição para o acesso e para o estabelecimento de cooperação vertical no canal de distribuição. Nesse caso, os benefícios observados estão relacionados à maior eficiência no suprimento de produtos, pois há diminuição da incerteza da transação, redução das falhas no suprimento e aumento na conformidade de pedidos, mesmo quando contratos formais não estão presentes.

Com base na pesquisa, verificou-se que a cooperação entre grupos de produtores e seus parceiros de negócios envolve a adoção de mecanismos de incentivo por ambas as partes. Esses incentivos podem ser iniciativas do fornecedor (grupo de produtores) ou do cliente. $\mathrm{O}$ fornecimento de assistência técnica, $\mathrm{o}$ compartilhamento de informações como expectativas de vendas, o pagamento de preço-prêmio pelos produtos e a participação conjunta no planejamento da produção, entre outros, podem ser citados como mecanismos de incentivo por parte dos clientes. Já a participação na promoção do produto para o consumidor final e o compartilhamento de informações como expectativas de colheita são mecanismos de incentivo à cooperação por parte dos fornecedores.

Com base na teoria discutida, a equidade é uma variável muito relevante para que os grupos se mantenham coesos e seguros para cooperarem. Entretanto, foram observados casos em que os 
mecanismos de incentivo eram contrários à equidade dentro do grupo. O pagamento de preços diferenciados em função da qualidade dos produtos é um exemplo de mecanismo de incentivo que dificulta a distribuição igualitária de benefícios entre os indivíduos. Nesses casos, se, por um lado, a falta de equidade pode resultar na possibilidade de conflitos e barreiras à cooperação, por outro lado os mecanismos de incentivo são importantes para induzir à ação coletiva.

Foi observado que os mecanismos de incentivo citados envolvem custos para seu estabelecimento. Assim, por que os agentes investem na cooperação? Com base na pesquisa empírica, diversos fatores estão relacionados com a necessidade dos agentes em cooperar para alcançar os seus objetivos individuais. Uma importante razão é a existência de incerteza em relação às transações. Essa incerteza está relacionada, principalmente, com a especificidade dos ativos demandados pelos clientes e com a possibilidade de oportunismo por parte dos seus fornecedores. São observados diferentes tipos de especificidade de ativos. A pesquisa revelou, principalmente, a ocorrência de especificidades física e temporal. A especificidade física dos produtos está relacionada, principalmente, com a quantidade demandada, com a diversidade de produtos e com a exigência de padrões de qualidade. Já a especificidade temporal dos produtos está relacionada com a necessidade de continuidade (regularidade) no fluxo de fornecimento de produtos.

O oportunismo, por sua vez, está relacionado com a interrupção do fluxo de fornecimento devido à opção dos fornecedores por outros canais de distribuição. Caso não haja continuidade das transações, o cliente tem um custo relacionado ao não atendimento da demanda por parte dos seus clientes e à busca por novos fornecedores. Para o fornecedor, a descontinuidade no fornecimento também representa custos de transação, traduzido em risco de perdas, porque implica a busca por outros canais e a adequação da sua produção às exigências de outros clientes.

Se, por um lado, o oportunismo aumenta a incerteza em relação à transação, por outro lado a confiança estabelecida entre os agentes tende a reduzir essas incertezas. A confiança é resultado da reputação construída ao longo do tempo. Essa variável facilita o estabelecimento de relacionamentos mais cooperativos. Assim, os agentes estabelecem esses relacionamentos porque consideram os custos de estabelecer e manter a cooperação vertical inferior ao custo da incerteza da transação. Destaca-se que a diminuição das incertezas é fator determinante para que o processo de tomada de decisões seja mais eficiente. Tanto as decisões gerenciais internas à firma quanto aquelas que envolvem o relacionamento entre os parceiros de negócios são beneficiadas por ambientes estáveis e por relacionamentos sustentáveis.

\section{Considerações finais}

As proposições da pesquisa foram testadas e corroboradas ao longo do trabalho.

P1: É possível identificar condicionantes para a cooperação envolvendo produtores de pequeno porte.

Com base na pesquisa empírica e na revisão de literatura identificou-se que existem variáveis que favorecem o estabelecimento da cooperação horizontal e vertical. Tais variáveis são de ordens social, econômica e gerencial e influenciam fortemente o estabelecimento e manutenção da cooperação entre os agentes.

P2: Há uma relação causal entre as variáveis de favorecem a ocorrência das ações coletivas.

Foi possível identificar empiricamente que as variáveis que influenciam a cooperação estão interrelacionadas. Esta consiste na maior contribuição para a área do conhecimento uma vez que há uma tendência para analisar o efeito de variáveis isoladas sobre a cooperação, desconsiderando interdependências e feedbacks. Sob o ponto de vista sistêmico, na medida em que há relações de causa e efeito entre as variáveis, mudanças nas variáveis decorrentes de causas externas ou do comportamento dos agentes levam a ajustes em todo o sistema. Dessa forma, interferências externas e decisões dos agentes afetam toda a ação coletiva.

Assim, a pesquisa revelou que são necessários investimentos para atender às demandas em relação a produtos e processos, o que dificilmente seria alcançado pelos produtores de forma isolada. Nesse caso, a cooperação pode proporcionar ganhos consideráveis, permitindo a inserção de produtores de pequeno porte em canais de distribuição. Os benefícios provenientes da cooperação horizontal e vertical resultaram em melhorias na capacidade de tomar decisões gerenciais mais acuradas e, consequentemente, na melhoria da eficiência individual e do canal de distribuição em que estavam inseridos.

Dessa forma, observou-se que a cooperação horizontal foi condição básica para que fosse estabelecida a cooperação vertical entre os agentes, pois as transações envolvem especificidades difíceis de serem alcançadas por produtores individuais, principalmente, considerando-se as dificuldades encontradas por produtores de pequeno porte.

Constata-se que a cooperação horizontal e vertical pode proporcionar melhorias que permitam acesso ao mercado sem que isso implique profundas transformações da pequena unidade de produção, como a redução de mão de obra e o aumento da área ou da produtividade. Os pequenos produtores rurais podem estar inseridos no mercado, conservando as características da pequena propriedade rural como pequena escala, área reduzida de produção e utilização de mão de obra intensiva. Assim, é possível que os produtores tenham acesso a mercados e continuem pequenos, se assim o desejarem, por 
meio do estabelecimento de relacionamentos interorganizacionais baseados na cooperação horizontal e vertical.

Assim, percebe-se que a cooperação horizontal e vertical consiste numa alternativa para pequenos produtores rurais, como identificado por Farina (2002), Ramírez e Berdegué (2003). Entretanto, a cooperação demanda investimentos de ambas as partes para evitar as barreiras identificadas na literatura (OLSON, 2001; MATOPOULUS; VLACHOPOULOU; MANTHOU, 2007) e observadas na pesquisa empírica, como a heterogeneidade dos grupos, poder e confiança, entre outras. Uma vez capazes de transpor essas barreiras, com a utilização de sistemas colaborativos baseados no ganho compartilhado entre os agentes, espera-se que os produtores rurais sejam beneficiados no sentido de serem capazes de escolher o canal mais adequado para o escoamento da sua produção. Dessa forma, problemas econômicos e sociais, como a exclusão, pobreza e êxodo rural decorrentes da sua dificuldade de acesso aos principais canais de distribuição, poderiam ser evitados por meio da geração de renda. Os consumidores, entretanto, podem ser beneficiados à medida que a inserção desses fornecedores proporcionaria a oferta de alimentos em quantidade e qualidade socialmente desejáveis.

\section{Agradecimentos}

Capes, CNPq e FAPESP.

\section{Referências}

ALTERBURG, T.; MEYER-STAMER, J. How to promote clusters: policy experiences from Latin America. World Development, v. 27, n. 9, p. 1693-1713, 1999.

AMATO NETO, J. Redes de cooperação produtiva e clusters regionais: oportunidades para as pequenas e médias empresas. São Paulo: Atlas, 2000. 163 p.

ANDERSON, V.; JOHNSON, L. Systems thinking basics: from concepts to causal loops. Cambridge, Massachusetts: Pegasus Communications, 1997. 133 p.

BAKER, W. E. Fragments of a cognitive theory of technological change and organizational structure. In: NOHIA, N.; ECCLES, R. G. Networks and organizations: structure, form and action. Boston: Harvard Business School Press, 1992. 544 p.

BARDIN, L. Análise de Conteúdo. Lisboa: Edições 70, 2008. 288 p.

BATT, P. F. Building trust between growers and market agents. Supply Chain Management: an international journal, v. 8, n. 1, 2003.

BOHMAN, H.; BOTER, H.; TESAR, G. Beyond Networking: a case study of rigorous cooperation among sme's. In: Annual IMP Conference, 19., 2003, Lugano, Switzerland. Anais... Disponível em: <http:// www.impgroup.org >. Acesso em: 22 jul. 2004.

BRASS, D. J.; BURKHARDT, M. E. The strenth of strong ties: the importance of philos in organizations. In: NOHIA, N.; ECCLES, R. G. Networks and organizations: structure, form and action. Boston: Harvard Business School Press, 1992. 544 p.

BRITO, C. M. Towards an institutional theory of the dynamics of industrial network. Journal of Business \& Industrial Marketing, v. 16, n. 3. p. 150-166, 2001.

BRITTO, J. Cooperação interindustrial e redes de empresas. In: KUPFER, D.; HASENCLEVER, L. Economia industrial: fundamentos teóricos e práticas no Brasil. Rio de Janeiro: Campus, 2002. 688 p.

BURGER, K.; KAMEO, D.; SANDEE, H. Clustering of small agro-processing firms in Indonesia. International Food and Agribusiness Management Review, v. 2, n. 2/3, 2001.

CHIRIBOGA, M. Comercialización y pequenõs productores. Estudio elaborado para FIDAMÉRICA. Quito, 2007.

CLARO, D. P. Managing business networks and buyersupplier relationship: how information obtained from the business network affects trust, transaction specific investments, collaboration and performance in the Dutch potted plant and flower industry. 2004. Tese (Doutorado)-Wageningen University and Research Centre, Wageningen, 2004.

COLEMAN, J. S. Social capital in the creation of human capital. American Journal of Sociology, v. 94, Supplement., p. S95-S120, 1988.

DYER, J. H. Effective interfirm collaboration: how firms minimize transaction costs and maximize transaction value. Strategic Management Journal, v. 18, n. 7, p. 535-556, 1997.

FARINA, E. M. M. Q. Consolidation, multinationalisation, and competition in Brazil: impacts on horticulture and dairy products systems. Development Policy Review, v. 4, n. 20, p. 441-457, 2002.

FORRESTER, J. Industrial Dynamics. Portland: Productivity Press, 1961. 464 p.

FUTEMMA, C. et al. The emergence and outcomes of collective action: an institutional and ecosystem approach. Ambiente \& Sociedade, v. 5, n. 19, 2002.

GRANDORI, A.; SODA, G. Inter-firm networks: antecedents, mechanisms and forms. Organizations studies, v. 2, n. 16, p.183-214, 1995.

HAKANSSON, H. Industrial technological development: a network approach. London: Croom Helm, 1992.

HAKANSSON, H.; FORD, D. How should companies interact in business networks? Journal of Business Research, v. 55, p. 133-139, 2002.

HARDMAN, P. A.; DARROCH, M. A. G.; ORTMANN, G. F. improving cooperation to make the South Africa fresh apple export value chain more competitive. Journal on chain and network science, v. 2, n. 1, p. 61-72, 2002.

HEIDE, J. B. Interorganizational governance in marketing channels. Journal of marketing, v. 48, p. 71-85., 1994.

HUMPHREY, J. Is commercial agriculture becoming too challenging to small farmers? Disponível em: <http://www.princeton.edu/ piirs/trading_morsels/ papers/humphrey.pdf>. Acesso em: $17 \mathrm{dez} .2005$.

HUMPHREY, J.; OETERO, A. Strategies for diversification and adding value to food exports: a value chain perspective. Institute of Development Studies, University 
of Sussex. UNCTAD - United Nations Conference on Trade and Development, 2000.

KOTZAB, H.; TELLER, C. Value-adding partnerships and co-opetition models in the grocery industry. International Journal of Physical Distribution \& Logistics Management, v. 33, n. 3, p. 268-281, 2003. LAZZARINI, S. G.; CHADDAD, F.; COOK, M. L. Integrating supply chain and network analysis: the study of netchains. Journal on Chain and Network Science, v. 1, n. 1, p. 7-22. 2001.

MACHADO, M. D. Canais de distribuição para produtos da agricultura familiar: um estudo em hortaliças. 2004. Dissertação (Mestrado em Engenharia de Produção)Universidade Federal de São Carlos, São Carlos, 2004.

MATOPOULUS, A.; VLACHOPOULOU, M.; MANTHOU, V. A conceptual framework for supply chain collaboration: empirial evidence from the agri-food industry. Supply Chain Management: an international journal, n. 12/3, 2007.

MURDOCH, J. Networks: a new paradigm of rural development? Journal of Rural Studies, v. 16, p. 407-419, 2000.

NASSAR, A. M.; ZYLBERSZTAJN, D. Associações de interesse no agronegócio brasileiro: análise das estratégias coletivas. Revista de Administração, v. 39, n. 2, 2004.

NOHIA, N.; ECCLES, R. G. Networks and organizations: structure, form, and action. Boston: Harvard Business School Press, 1992. 544 p.

NORONHA VAZ, M. T. Agri-food small enterprises: coordination forms and the design of industrial models. 2002. Working paper. Mimeografado.

OLIVER, C. Determinants of interorganizational relationships: integration and future directions. Academy of Management Review, v. 15, n. 2, p. 241-265, 1990.

OLSON, M. The logic of collective action: public goods and the theory of groups. $19^{\text {th }}$ ed. Boston: Harvard University Press, 2001.

OMTA, S. W. F.; TRIENEKENS, J. H.; BEERS, G. Chain and Network Science: a research framework. Journal on Chain and Network Science, v. 1, n. 1, p. 1-6, 2001.

OSTROM, E. Governing the commons: the evolution of institutions for collective action. Cambridge: Cambridge University Press, 1990.

RAMÍREZ, E.; BERDEGUÉ, J. Acción coletiva y mejoras en las condiciones de vida de poblaciones rurales. Fundo Mink’a de Chorlaví. 2003. Disponível em: <http://www.fondominkachorlavi.org/ac/>. Acesso em: 12 maio 2004.

RING, P. S.; VAN DE VEN, A. H. Developmental processes of cooperative interorganizational relationships. Academy of Management Review, v. 19, n. 1. p. 90-118, 1994.

SABEL, C. F. Studied trust: building new forms of cooperation in a volatile economy. Human Relations, v. 46, n. 9, p. 1133-1170, 1993.

SAUVÉE, L. Strategic interdependence and governance: empirical evidence with two agri-food networks in the fresh and processed vegetable sectors in France. In: CONGRESSO INTERNACIONAL DE ECONOMIA E GESTÃO DE NEGÓCIOS; NETWORKS ALIMENTARES, 2001. Ribeirão Preto. Anais... Ribeirão Preto: USP/FEARP, 2001.

SEPPANEN, R.; BLOMQVIST, K.; SUNDQVIST, S. Measuring inter-organizational trust: a critical review of the empirical research in 1990-2003. Industrial Marketing Management, v. 36, n. 2, 2007.

SHEPHERD, A. Approaches to linking producers to markets: a review of experiences to date. Rome: Food and Agricultural Organization of United Nations, 2007. (Agricultural management, Marketing and Finance Occasional Paper, 13). Disponível em: <http://www. fao.org/ag/ags/subjects/en/agmarket/linkages/agsf13. html>. Acesso em: 10 jun. 2007.

SMITH-DOER, L.; POWELL, W. W. Networks and economic life. In: SMELSER, N. J.; SWEDBERG, R. The handbook of economic sociology. $2^{\text {nd }}$ ed. Princeton, NJ: Princeton University Press, 2005. Disponível em: <http://www.stanford.edu/group/song/papers/ NetworksandEconomicLife.pdf $>$. Acesso em: 30 out. 2007.

STERN, L. W.; EL-ANSARY, A. I.; COUGHLAN, A. T. Marketing channels. Englewood Cliffs: Prentice-Hall, 1996.

ZAHEER, A.; McEVILY, B.; PERRONE, V. Does trust matter? Exploring the effects of interorganizational and interpersonal trust on performance. Organization Science, v. 9, n. 2, p. 131-145, 1998.

ZINELDIN, M. A.; JONSSON, P. An examination of the main factors affecting trust/commitment in supplier-dealer relationships: an empirical study of the Swedish wood industry. The TQM magazine, v. 3, n. 4. p. 245-265, 2000. 